\title{
A DOMESTICAÇÃO DE ECRÃS NA INFÂNCIA: USOS E MEDIAÇÃO PARENTAL EM MEIOS CITADINO E RURAL
}

\author{
Carla Cruz \\ Centro de Administração e Políticas Públicas, Instituto Superior de Ciên- \\ cias Sociais e Políticas, Universidade de Lisboa, Portugal \\ Catarina Franco \\ Instituto Superior de Ciências Sociais e Políticas, Universidade de Lisboa, Portugal \\ Fábio Anunciação \\ Instituto Superior de Ciências Sociais e Políticas, Universidade de Lisboa, Portugal \\ Maria João Cunha \\ Centro Interdisciplinar de Estudos de Género, Instituto Superior de Ciên- \\ cias Sociais e Políticas, Universidade de Lisboa, Portugal
}

\begin{abstract}
Resumo
Este estudo procura caracterizar a utilização dos ecrãs no espaço doméstico em função dos contextos citadino e rural das crianças até aos cinco anos e conhecer como a família intervém na sua introdução e utilização. Para o efeito foram realizados quatro grupos de foco com crianças de quatro e cinco anos residentes na cidade de Lisboa e em Vila Pouca de Aguiar, no distrito de Vila Real e oito entrevistas semiestruturadas com pais e mães de ambos os contextos, chegando a várias conclusões: 1) as crianças do contexto rural são mais utilizadoras dos ecrãs em casa que as crianças da cidade; 2) os pais/mães de ambos os contextos são os responsáveis pelo acesso dos filhos aos ecrãs, sobretudo smartphones e tablets; 3) a principal explicação é a preocupação dos pais/mães com a exclusão social das crianças caso não os utilizem; 4) os progenitores/as do meio urbano denotam uma maior perceção dos riscos associados à exposição dos filhos aos dispositivos tecnológicos.
\end{abstract}

\section{SCREENS' DOMESTICATION IN CHILDHOOD: USES AND PARENTAL MEDIATION IN CITY AND RURAL CONTEXTS}

\begin{abstract}
The aim of this study was both to characterize screen use by children in domestic spaces depending on their urban or rural contexts and how their families intervene. For this purpose, four focus groups were applied to four- and five-year old children living in Lisbon and Vila Pouca de Aguiar, in Vila Real district. Eight parents from both contexts were interviewed. The main conclusions are: 1) in rural contexts, rather than in the city, children use more screens; 2) parents
\end{abstract}


from both contexts are accountable for children's access to screens, especially smartphones and tablets; 3 ) the main explanation is parents' concern with children's social exclusion in case they don't use screens; and 4) parents from urban context reveal more risk awareness concerning their children's exposure to technological devices.

\section{INTRODUÇÃo}

O ambiente doméstico está normalmente apetrechado com várias televisões, tablets, computadores e telemóveis, todos ligados à internet e à disposição de adultos e de crianças (Paudel, Jancey, Subedi \& Leavy, 2017). A televisão e o tablet são os dispositivos com que as crianças menores de cinco anos mais contactam (Köksalan, Aldim \& Göğebakan, 2019; Ponte, Simões, Batista, Castro \& Jorge, 2017). Os pequenos ecrãs nos lares ganharam expressão junto dos mais novos pela portabilidade, uso intuitivo e rápida capacidade de acesso a conteúdos variados (Kabali et al., 2015).

A exposição aos ecrãs ocorre desde bebés de meses, progredindo ao longo da infância e da juventude, e muitos acedem à tecnologia no quarto e veem televisão ou usam o tablet durante as refeições (Patraquim et al., 2018). Esta omnipresença dos ecrãs na infância, em especial entre as crianças pré-escolares (Duch, Fisher, Ensari \& Harrington, 2013) tem suscitado preocupação nas famílias e nos profissionais de saúde sobre possíveis efeitos no seu bem-estar (Bell, Bishop \& Przybylski, 2015; Domingues-Montanari, 2017). Esta "digitalização" da infância evoca questões sobre o significado, a disponibilidade e o uso desses media no quotidiano doméstico das crianças, não só para as proteger, como preparar a família para os novos desafios do cuidado parental (Cordeiro, 2015; Przybylski \& Weinstein, 2019).

Este estudo levanta duas questões: 1) como se caracteriza o uso de ecrãs nos lares de crianças em idade pré-escolar nos contextos citadino e rural?; 2) qual a perceção dos progenitores sobre as motivações subjacentes ao uso de ecrãs pelos seus filhos pequenos e da mediação que fazem, por consciência (ou não) dos riscos associados a esta faixa etária?

O meio rural é representado por Vila Pouca de Aguiar (daqui para diante designada V.P.A.), uma pequena vila do distrito de Vila Real, situada na província de Trás-os-Montes e Alto Douro, com pouco mais de 13 mil pessoas e o contexto urbano será representado pela capital portuguesa, Lisboa, a maior e mais populosa área metropolitana do país, onde residem mais de 547 mil pessoas (INE, 2011).

Neste artigo enfatizaram-se os riscos do uso de ecrãs na primeira infância, porque uma criança "não é um adulto em miniatura", necessitando de "ser protegida de qualquer forma de perigo" por parte dos seus cuidadores, pois não é capaz de fazer 
"escolhas integrais, dada a falta de conhecimentos, sabedoria e compreensão sistémica dos fenómenos" (Cordeiro, 2015, p. 110).

\section{ACESSO F CONSUMO DOS ECRÃS FM CONTEXTO DOMÉSTICO}

A televisão foi o primeiro ecrã a impor-se nos hábitos de consumo de media, "instalando-se" como uma espécie de babysitter das famílias (Beyens \& Eggermont, 2014). Com o avançar do século XXI, a audiência televisiva decresceu em todos os segmentos etários (Cardoso, Mendonça, Paisana, Lima \& Neves, 2015), partilhando a atenção das crianças com os ecrãs digitais de pequeno porte e tácteis, e com acesso a aplicações diversificadas (Kabali et al., 2015; Ponte et al., 2017).

Em Portugal também existe um ambiente tecnológico maior nos lares onde residem crianças (INE, 2015), facilitando uma exposição superior ao que é recomendado (Council on Communications and Media, 2013). O estudo Happy kids (Dias \& Brito, 2018) concluiu que as crianças menores de dois anos são as mais utilizadoras de smartphones e tablets, por impulsionamento da família. As autoras perceberam que a televisão já não é uma "ama eletrónica", mas um mero "barulho de fundo" que divide a atenção com outros ecrãs. Brito (2018) mostrou que as crianças com menos de seis anos já dão preferência ao tablet e muitas delas têm um para uso pessoal. No entanto, verificou que a televisão continua ligada num canal infantil, ainda que em paralelo com o uso do tablet ou do smartphone (de um dos progenitores). Patraquim et al. (2018) confirmaram que a exposição desses ecrãs ocorre desde bebés de meses, progredindo ao longo da infância e da juventude, seja no quarto ou durante as refeições. A idade é, por isso, a variável central na análise desta sociedade multimédia (Cardoso et al., 2015), com a presença de media interativos cada vez mais cedo e com um impacto significativo na vida das crianças (Ariani, Putu, Aditya, Endriyani \& Niati, 2017).

As crianças desta era digital foram designadas de "digitods" por Holloway, Green e Stevenson (2015). O facto de os pais serem os primeiros "nativos digitais" (Prensky, 2001) facilita a integração desse habitus nos quotidianos dos filhos e até com certo entusiasmo e orgulho por estes a utilizarem com independência e destreza (Plowman, McPake \& Stephen, 2010). Quando a família é consumidora ativa de ecrãs, há uma grande probabilidade de projetar, nos filhos uma perceção positiva a respeito da utilidade e do prazer no uso desses dispositivos (Kabali et al., 2015). Daí a oferta e o uso de tablets e smartphones a crianças ocorrer no quotidiano familiar: recompensa pelo bom comportamento ou resultados escolares; para as distrair enquanto comem ou se vestem; para as ocuparem durante tarefas ou descanso dos pais; para facilitar a hora de dormir; para controlar "birras" ou como apoio educacional (Dias \& Brito, 2018; Kabali et. al., 2015; Ponte et al., 2017).

Para Ponte e Vieira (2008) a utilização destes instrumentos com recurso à internet, quando bem usados, conduzem a melhores resultados escolares, facilitam o acesso à informação e ao entretenimento e promovem a interação e a integração dos mais novos. Contudo, os autores destacaram a importância de monitorizar o tempo de uso, o 
conteúdo consumido, o tipo de interação e quem participa nela. Sobretudo, no caso de crianças mais novas, pois a sobre-estimulação afeta o seu bem-estar mental/psicológico, social e físico (Kardefelt-Winther, 2017). Estados depressivos, fraca linguagem, menor curiosidade, frustração, obesidade, problemas de visão e de sono, etc., são efeitos possíveis (e.g. Gottschalk, 2019; Kardefelt-Winther, 2017; Twenge \& Campbell, 2018).

Çetintaş e Turan (2018) perceberam que as crianças com idade pré-escolar usam intensivamente os dispositivos digitais e manuseiam-nos facilmente, mas ignoram os possíveis perigos associados ao conteúdo. À família cumpre exercer o papel instrumental na gestão do acesso aos ecrãs móveis pelas crianças e no acompanhamento dos conteúdos a que acedem (Nikken, 2019). Sobretudo, os menores de cinco anos que estão absolutamente dependente dos cuidadores para acederem à tecnologia (Ofcom, 2019).

Os pais, na mediação da utilização dos diferentes media pelos filhos, devem restringir a exposição máxima diária de uma a duas horas, proibir qualquer ecrã a crianças com menos de dois anos, não permitir qualquer ecrã no quarto das crianças, monitorizar o que é visionado e discutir os valores e ideais abordados nesses conteúdos (Council on Communications and Media, 2013).

\section{A MEDIAÇÃo PARENTAL NO CONSUMO DE ECRÃS POR CRIANÇAS NOS LARES}

Na generalidade, as famílias tendem a seguir estratégias para mediar a utilização de ecrãs desde a infância, atuando em função do presente e de como pretendem que eles os utilizem no futuro (Livingstone, Mascheroni, Dreier, Chaudron \& Lagae, 2015). Domoff et al. (2019) demonstram que a mediação dos pais está associada a melhores desempenhos na infância.

A primeira tipologia de mediação baseada no consumo televisivo e da internet no computador identificava três estratégias de ação: ativa que estimula a descodificação crítica de conteúdos com a criança; restritiva que limita e impõe regras sobre o tempo de utilização e os conteúdos que a criança pode aceder e co-uso; promovendo a utilização conjunta da tecnologia (Nathanson, 1999). Com o aparecimento dos novos ecrãs com um uso mais individualizado, dada a sua dimensão e portabilidade, a rede europeia "EU Kids Online" (Livingstone et al., 2015) identificou cinco estilos de intervenção parental: mediação ativa (que integrou a em co-uso), com partilha e discussão ao longo das atividades online; mediação de segurança, baseada no aconselhamento e orientação relativamente aos riscos; mediação restritiva, cingida a regras e proibições; mediação técnica, que se apoia no uso de filtros para barrar o acesso a certos canais e conteúdos e; mediação por monitoramento, em que os pais verificam o histórico do computador, o acesso e contactos nas redes sociais, telefones, etc.

Mendonza (2009) refere que a mediação restritiva e ativa dos pais está associada a resultados mais positivos para o desenvolvimento da criança, porque: 1) as crianças serão menos expostas a conteúdo inapropriado nos ecrãs; 2 ) tornam-se mais críticas sobre os conteúdos mediáticos em geral; 3) tenderão a privilegiar conteúdos educativos; 4) geram melhores desempenhos na escola. $\mathrm{O}$ autor acrescentou que a mediação parental 
em co-utilização promove efeitos positivos no vínculo parental e no desenvolvimento de gostos culturais dos filhos. Livingstone e Byrne (2018) descobriram que uma mediação parental mais favorável foi associada positivamente tanto às oportunidades, como à possibilidade de mais riscos durante a experiência online das crianças. Já a mediação mais restritiva foi associada a menos riscos, mas também a menos oportunidades online vivenciadas pelas crianças.

A mediação parental pode ser influenciada pelo género, idade da criança, pelo estatuto socioeconómico familiar, bem como pelo estilo parental (Livingstone \& Helsper, 2008). Baumrind (1991) apresentou vários estilos parentais: a parentalidade rigorosa, em que os pais são mais receptivos, mas exigentes; a parentalidade autoritária, caracterizada por um elevado controlo e baixa afetividade; a parentalidade permissiva, com um perfil acolhedor, solidário e pouco exigente; e a parentalidade laissez-faire, sem envolvimento e capacidade de resposta.

Apesar dos estilos de mediação existentes, é impossível para os pais intervirem ininterruptamente ao longo de 24 horas, dada a omnipresença de dispositivos e conteúdos digitais em casa, e as múltiplas tarefas que têm de cumprir fora e dentro do lar (Nomaguchi, 2009). Para não se sentirem tão assoberbados, muitos progenitores/ as tendem a investir menos na mediação parental e a confiar mais na tecnologia para manterem os filhos ocupados, sobretudo quando os aborrecimentos diários excedem os seus recursos de tempo, espaço, energia e finanças (Evans, Jordan \& Horner, 2011). É que limitar o uso dos media também exige que os pais possam oferecer fontes alternativas de entretenimento aos filhos (Evans et al., 2011) e tenham conhecimento suficiente para gerenciar a tecnologia e/ou os conteúdos a que os filhos acedem (Nevski \& Siibak, 2016; Nikken \& de Haan, 2015).

E se há contextos sociais em que os irmãos mais velhos garantem, na ausência ou indisponibilidade dos pais, a orientação do uso de media pelos irmãos mais novos, ensinando a usar aplicações inteligentes e escolhendo conteúdos adequados para a sua idade (Nevski \& Siibak, 2016), há outros em que só complicam mais, expondo a criança mais nova a conteúdos inapropriados para a faixa etária (Nikken \& de Haan, 2015).

Blum-Ross e Livingstone (2018) anuem que os pais/mães vivem hoje um paradoxo. Ora sentem dificuldade e preocupações, reforçadas por muitos especialistas, pelo influxo irreversível dos media digitais na infância dos filhos, reconhecendo que o tempo de exposição a esses dispositivos está a prejudicá-los física e mentalmente, ora desfrutam das oportunidades, prazeres e conveniências do "mundo" digital no seu quotidiano. E além desse desfrute corrente, os pais projetam-se num futuro que exigirá aos filhos as "habilidades do século XXI".

\section{ESPECIFICIDADES SOCIODEMOGRÁFICAS DA EXPOSIÇÃO E MEDIAÇÃO DOS ECRÃS DOMÉSTICOS}

A experiência de consumo dos media varia conforme as diferentes realidades sociais, culturais, políticas e económicas das regiões. Livingstone, já em 1998, percebeu várias divergências em países da Europa. Por exemplo, duas em cada três crianças 
britânicas tinham televisão no quarto, o que contribuiu para o processo de individualização e fragmentação social dos lares. Kabali et al. (2015) também evidenciaram que crianças de zonas urbanas são as que possuem acesso quase total a ecrãs móveis e, grande parte delas, possuem um dispositivo próprio desde os quatro anos.

Ponte et al. (2017) estabeleceram uma relação com o nível socioeconómico das famílias, e viram que o consumo televisivo das crianças é maior nos lares com baixos rendimentos, enquanto aquelas que pertencem a um estrato económico superior possuem mais acesso à internet nos vários dispositivos existentes no espaço doméstico. A este propósito, Harris et al. (2018) verificaram que as crianças economicamente desprovidas, sobretudo quando pertencem a minorias étnicas, tendem a apresentar um défice de "Iiteracia digital", por falta de acesso a dispositivos e a conteúdos conectados à internet.

Clark (2013) analisou a presença, uso e mediação da tecnologia nos lares americanos, em função do nível de rendimento e escolaridade das famílias, concluindo que estas variáveis, em conjunto, influenciam a desigualdade no contexto tecnológico. Quando cruzou baixos rendimentos e baixa instrução encontrou uma aquisição acima da média de dispositivos nos lares, acompanhada por uma lacuna geracional nas experiências digitais e, por isso, os pais mostravam-se, ambivalentemente, preocupados e restritivos. Já quando relacionou baixo rendimento com níveis altos de instrução verificou uma heterogeneidade tecnológica, com lares muito e pouco equipados. Foi nesta relação que encontrou a proporção mais alta de famílias monoparentais, e em que pai (ou mãe) tinha confiança nas suas habilidades digitais e nas capacidades de mediação, privilegiando estratégias restritivas e ativas. Na combinação mútua de rendimento familiar e nível de instrução elevados, percebeu uma "ética de empoderamento expressivo", com práticas e estratégias diversas para gerenciar as restrições do uso de dispositivos digitais e a promoção de atividades offline em casa e, sobretudo, no exterior. Estas famílias também tendem a trabalhar com meios digitais em casa, tendo consciência que isso dificulta a limitação do uso de ecrãs digitais pelos filhos.

Weber e Mitchell (2008) também referem que nem todas as crianças vivem rodeadas de tecnologia e que há casas com recursos económicos que não possuem computadores, telemóveis, $\mathrm{mp} 3$ ou mesmo PlayStation, estando as crianças envolvidas em atividades desportivas, a socializar com amigos ou a ler livros.

\section{NotA METODOLÓGICA}

Para responder às questões levantadas, desenvolveu-se uma abordagem qualitativa exploratória através de sessões de grupos focais com crianças de V.P.A. e de Lisboa e de entrevistas semiestruturadas com progenitores/as de ambos os espaços, realizadas ao longo do mês de abril de 2019. Para permitir a comparação entre os usos de ecrãs e as estratégias de mediação abordados por ambas as técnicas procurou constituir-se painéis com agregados familiares com níveis de rendimento semelhantes em ambos os espaços, ainda que a formação académica seja globalmente mais elevada entre os progenitores de Lisboa (Tabela 3). Os nomes atribuídos às crianças e aos pais/mães são fictícios para proteger a identidade dos participantes. 
Assim, foram realizadas quatro sessões de grupos focais com 10 crianças de Lisboa e 10 crianças, de V. P. A. de quatro e cinco anos, divididas por género. Decidiu-se fazer sessões separadas com meninas e meninos para prevenir eventuais inibições das crianças no debate sobre o uso que fazem dos ecrãs em casa e, sobretudo, sobre os conteúdos que consomem. Para aumentar as interações entre sujeitos com capacidade de expressão limitada, reuniu-se o número mínimo aconselhado para grupos focais (Bryman, 2016). As crianças com menos de quatro anos não foram incluídas pelas dificuldades de linguagem inerentes à idade.

Os tópicos para discussão foram organizados por: contexto familiar; presença de ecrãs em casa; posse e/ou acesso dos ecrãs pelas crianças; conteúdos que mais veem nos vários ecrãs a que acedem; intervenções parentais associadas ao uso e à exposição de conteúdos; e a prática de outras formas de entretenimento (tradicionais). A aplicação do "guião" seguiu todos os procedimentos éticos, em jeito de conversa informal. Previamente às sessões foi explicado o intuito do estudo e os procedimentos aos adultos responsáveis e todas as crianças participaram com autorização formalizada dos pais e dos educadores.

As sessões decorreram no jardim-de-infância do agrupamento de escolas de V.P.A. e nas Atividades de Tempos Livres (ATL) da Freguesia de Santo António, em Lisboa. Recorreu-se ao ATL da zona escolar por a recolha de dados, em Lisboa, ter coincidido com as férias da Páscoa e os jardins-de-infância do agrupamento estarem encerrados.

Em paralelo foram inquiridos, por entrevista semiestruturada, dois painéis com quatro pais/mães de crianças, escolhidos de acordo com dois critérios: terem filhos entre os zero e os cinco anos e residirem numa das duas regiões deste estudo. $O$ guião foi organizado por questões contextuais, a presença de ecrãs em casa; a idade em que permitiram os filhos usar os ecrãs no espaço doméstico; a mediação utilizada na utilização e na exposição do conteúdo e as preocupações parentais associadas. Os agregados familiares destes pais/mães são genericamente de estrutura nuclear, com exceção de um pai de V.P.A., cujo agregado familiar integra também a avó e bisavó, e um pai de Lisboa que vive só com a filha. As idades dos entrevistados variam entre os 29 e os 39 anos e a dos seus filhos/as entre os seis meses e os quatro anos.

As Tabelas 1 e 2 resumem a informação contextual sobre as crianças dos grupo de foco e a Tabela 3 a dos progenitores/as residentes em V.P.A. e em Lisboa, respetivamente.

\begin{tabular}{|c|c|c|c|c|}
\hline \multicolumn{5}{|c|}{ Vila Pouca de Aguiar } \\
\hline “Pedro" & “Tiago" & “Rodrigo" & “José" & “Miguel” \\
\hline Cinco anos & Quatro anos & Cinco anos & Quatro anos & Cinco anos \\
\hline $\begin{array}{l}\text { - Vai para casa depois } \\
\text { da escola, numa } \\
\text { carrinha da câmara. } \\
\text { - Vive com a } \\
\text { mãe e o pai. } \\
\text { - Não tem atividades } \\
\text { extra-curriculares. }\end{array}$ & $\begin{array}{l}\text { - A avó é quem o } \\
\text { vai buscar à escola } \\
\text { e fica em sua casa } \\
\text { até a mãe chegar do } \\
\text { trabalho (sai àsı } 8 \mathrm{~h} \text { ). } \\
\text { - Vive com a } \\
\text { mãe e o pai. } \\
\text { - Não tem atividades } \\
\text { extra-curriculares. }\end{array}$ & $\begin{array}{l}\text { - A mãe é quem o } \\
\text { vai busca à escola } \\
\text { e vão para casa. } \\
\text { - Vive com a mãe, } \\
\text { o pai e a irmã, de } \\
\text { sete meses. } \\
\text { - Não tem atividades } \\
\text { extra-curriculares. }\end{array}$ & $\begin{array}{l}\text { - O pai é quem o } \\
\text { vai buscar à escola } \\
\text { e vão para casa. } \\
\text { - Vive com a } \\
\text { mãe e o pai. } \\
\text { - Não tem atividades } \\
\text { extra-curriculares. }\end{array}$ & $\begin{array}{l}\text { - Vai para casa depois } \\
\text { da escola, numa } \\
\text { carrinha da câmara. } \\
\text { - Vive com a } \\
\text { mãe e o pai. } \\
\text { - Não tem atividades } \\
\text { extra-curriculares. }\end{array}$ \\
\hline
\end{tabular}




\begin{tabular}{|c|c|c|c|c|}
\hline "Beatriz" & “Cláudia" & "Benedita" & "Gabriela" & "Inês Leonor" \\
\hline Cinco anos & Cinco anos & Quatro anos & Quatro anos & Cinco anos \\
\hline $\begin{array}{l}\text { - A mãe é quem a vai } \\
\text { buscar à escola. } \\
\text { - Vive com a mãe, } \\
\text { o pai e a irmã, de } \\
\text { seis meses. } \\
\text { - Tem taekwondo às ter- } \\
\text { ças, quartas e quintas- } \\
\text {-feiras, até às 18h3o. }\end{array}$ & $\begin{array}{l}\text { - A mãe é quem a } \\
\text { vai busca à escola } \\
\text { e vão para casa. } \\
\text { - Vive com a } \\
\text { mãe e o pai. } \\
\text { - Não tem atividades } \\
\text { extra-curriculares. }\end{array}$ & $\begin{array}{l}\text { - O pai é quem a } \\
\text { vai buscar à escola } \\
\text { e vão para casa. } \\
\text { - Vive com a mãe, o pai } \\
\text { e a irmã, de nove anos. } \\
\text { - Não tem atividades } \\
\text { extra-curriculares. }\end{array}$ & $\begin{array}{l}\text { - A mãe é quem a } \\
\text { vai busca à escola } \\
\text { e vão para casa. } \\
\text { - Vive com a mãe, o pai } \\
\text { e o irmão, de } 12 \text { anos. } \\
\text { - Tem taekwondo às ter- } \\
\text { ças, quartas e quintas- } \\
\text {-feiras, até às } 18 \text { h3o. }\end{array}$ & $\begin{array}{l}\text { - A mãe é quem a } \\
\text { vai busca à escola } \\
\text { e vão para casa. } \\
\text { - Vive com a mãe } \\
\text { e com o pai. } \\
\text { - Tem karaté às } \\
\text { segundas e quin- } \\
\text { tas até às } 18 \mathrm{~h} \text {. }\end{array}$ \\
\hline
\end{tabular}

Tabela 1: Caracterização das crianças residentes em Vila Pouca de Aguiar (Vila Real)

\begin{tabular}{|c|c|c|c|c|}
\hline \multicolumn{5}{|c|}{ LISBOA } \\
\hline “João" & "Martim" & "Duarte" & “Lucas" & "Afonso" \\
\hline Cinco anos & Quatro anos & Quatro anos & Quatro anos & Quantro anos \\
\hline $\begin{array}{l}\text { - A mãe é quem o } \\
\text { vai busca à escola } \\
\text { e vão para casa. } \\
\text { - Vive com os pais e } \\
\text { com os irmãos, de } \\
11, \text { oito e dois anos. } \\
\text { - Não tem atividades } \\
\text { extra-curriculares. }\end{array}$ & $\begin{array}{l}\text { - A avó é quem o vai } \\
\text { buscar à escola e fica } \\
\text { com ela até a mãe } \\
\text { sair do trabalho. } \\
\text { - Vive só com os pais. } \\
\text { - Não tem atividades } \\
\text { extra-curriculares. }\end{array}$ & $\begin{array}{l}\text { - Ambos os pais o } \\
\text { vão buscar à escola. } \\
\text { - Vive com os pais } \\
\text { e os irmãos, de } \\
\text { oito e dois anos. } \\
\text { - Pratica futebol às } \\
\text { terças e quintas. }\end{array}$ & $\begin{array}{l}\text { - Ambos os pais o } \\
\text { vão buscar à escola } \\
\text { e vão para casa. } \\
\text { - Vive com os pais e } \\
\text { a irmã, de } 11 \text { anos. } \\
\text { - Não tem atividades } \\
\text { extra-curriculares }\end{array}$ & $\begin{array}{l}\text { - Ambos os pais o } \\
\text { vão buscar à escola. } \\
\text { - Vive com os pais e } \\
\text { a irmã, de seis anos. } \\
\text { - Tem natação duas } \\
\text { vezes por semana. }\end{array}$ \\
\hline "Eva" & "Carolina" & "Amélia" & "Sofia" & "Violeta" \\
\hline Quatro anos & Cinco anos & Quatro anos & Cinco anos & Cinco anos \\
\hline $\begin{array}{l}\text { - A mãe é quem a vai } \\
\text { buscar à escola. } \\
\text { - Vive com os pais } \\
\text { e as irmãs, de um, } \\
\text { sete e } 11 \text { anos. } \\
\text { - Tem ginástica às } \\
\text { terças e quintas. }\end{array}$ & $\begin{array}{l}\text { - Ambos os pais a } \\
\text { vão buscar à escola. } \\
\text { - Vive com os pais e o } \\
\text { irmão, de quatro anos. } \\
\text { - Tem natação à } \\
\text { quarta-feira }\end{array}$ & $\begin{array}{l}\text { - A mãe é quem a vai } \\
\text { buscar à escola. } \\
\text { - Vive com a mãe } \\
\text { durante a semana e } \\
\text { com o pai e os irmãos, } \\
\text { de } 12 \text { e } 21 \text { anos aos } \\
\text { fins de semana. } \\
\text { - Tem ginástica artísti- } \\
\text { ca às terças e quintas. }\end{array}$ & $\begin{array}{l}\text { - A mãe é quem a vai } \\
\text { buscar à escola. } \\
\text { - Vive com os pais } \\
\text { e as irmãs, de dois, } \\
\text { quatro e } 11 \text { anos. } \\
\text { - Tem ginástica às } \\
\text { terças e quintas e } \\
\text { aulas de inglês às } \\
\text { quartas e sextas. }\end{array}$ & $\begin{array}{l}\text { - A mãe é quem a vai } \\
\text { buscar à escola. } \\
\text { - Vive com os pais e o } \\
\text { irmão, de dois anos. } \\
\text { - Tem natação } \\
\text { às sextas. }\end{array}$ \\
\hline
\end{tabular}

Tabela 2: Caracterização das crianças residentes em Lisboa

\begin{tabular}{|c|c|c|c|}
\hline \multicolumn{4}{|c|}{ Vila Pouca de Aguiar } \\
\hline Pai “António” & Pai “Carlos” & Mãe “Madalena” & Mãe “Judite” \\
\hline $\begin{array}{l}\text { - } 37 \text { anos; } \\
-7^{\circ} \text { ano de escolaridade; } \\
\text { - jardineiro. }\end{array}$ & $\begin{array}{l}\text { - } 35 \text { anos; } \\
-9^{\circ} \text { ano de escolaridade; } \\
\text { - comerciante. }\end{array}$ & $\begin{array}{l}\text { - } 39 \text { anos; } \\
\text { - licenciada; } \\
\text { - professora. }\end{array}$ & $\begin{array}{l}-29 \text { anos; } \\
-12^{\circ} \text { ano de escolaridade; } \\
\text { - assistente geriátrica. }\end{array}$ \\
\hline $\begin{array}{l}\text { Trabalha de segunda a } \\
\text { sexta-feira das gh às } 18 \mathrm{~h} \text {. } \\
\text { Agregado familiar composto } \\
\text { por ele, a mulher os dois fi- } \\
\text { Ihos (três e } 14 \text { anos) e ainda } \\
\text { pela sogra e mãe da sogra. } \\
\text { Tempo com a criança: cerca } \\
\text { de duas a três horas por } \\
\text { dia (chega a casa perto } \\
\text { das } 19 \text { h3o e a criança mais } \\
\text { nova deita-se às } 21 \mathrm{~h} \text { ). }\end{array}$ & $\begin{array}{l}\text { Trabalha sete dias por semana } \\
\text { das } 7 \text { h3o às } 15 \mathrm{~h} \text {. Agregado } \\
\text { familiar composto por ele, pela } \\
\text { mulher e pela filha (três anos). } \\
\text { Tempo com a criança: diaria- } \\
\text { mente vai buscá-la ao ATL, por } \\
\text { volta das } 17 \mathrm{~h} \text { e passa o resto } \\
\text { do dia com ela, até a criança } \\
\text { se deitar perto das } 21 \mathrm{~h} \text {. }\end{array}$ & $\begin{array}{l}\text { Trabalha de segunda } \\
\text { a sexta-feira, cerca de } \\
\text { seis horas por dia. } \\
\text { Agregado familiar composto } \\
\text { por ela, pelo marido e pelos } \\
\text { dois filhos (três e oito anos). } \\
\text { Tempo com acriança: todo } \\
\text { o que decorre entre as } 17 \mathrm{~h} \text {, } \\
\text { saída do infantário, até à } \\
\text { hora de deitar, perto das } 21 \mathrm{~h} \text {. }\end{array}$ & $\begin{array}{l}\text { Trabalha oito horas de } \\
\text { segunda a sexta-feira (7h } \\
\text { às } 15 \mathrm{~h} \text { ). Agregado familiar } \\
\text { composto por ela, pelo } \\
\text { marido e pelos dois filhos } \\
\text { (um e nove anos). } \\
\text { Tempo com a crian- } \\
\text { ça: todo o que decorre } \\
\text { entre as } 15 \mathrm{~h} \text {, até à hora } \\
\text { de deitar, perto das } 21 \mathrm{~h} \text {. }\end{array}$ \\
\hline
\end{tabular}




\begin{tabular}{|c|c|c|c|}
\hline \multicolumn{4}{|c|}{ LISBOA } \\
\hline Pai “Pedro” & Pai “Miguel” & Mãe “Marta” & Mãe “Vera” \\
\hline $\begin{array}{l}\text { - } 30 \text { anos; } \\
\text { - licenciado; } \\
\text { - treinador infantil de fute- } \\
\text { bol, professor de Atividades }\end{array}$ & $\begin{array}{l}\text { - } 31 \text { anos; } \\
\text { - licenciado; } \\
\text { - carteiro. }\end{array}$ & $\begin{array}{l}\text { - } 35 \text { anos; } \\
\text { - licenciada; } \\
\text { - jornalista. }\end{array}$ & $\begin{array}{l}\text { - } 32 \text { anos; } \\
\text { - licenciada; } \\
\text { - auxiliar de educação. }\end{array}$ \\
\hline $\begin{array}{l}\text { de Enriquecimento Curricu- } \\
\text { lar e cronista do Expresso. }\end{array}$ & $\begin{array}{l}\text { Trabalha de segunda a sexta- } \\
\text {-feira, oito horas por dia. }\end{array}$ & $\begin{array}{l}\text { Trabalha oito horas por dia } \\
\text { durante os dias da semana. }\end{array}$ & $\begin{array}{l}\text { Trabalha por turnos } \\
\text { de sete horas. }\end{array}$ \\
\hline $\begin{array}{l}\text { Trabalha sete dias por sema- } \\
\text { na com horários variados. }\end{array}$ & $\begin{array}{l}\text { Agregado familiar compos- } \\
\text { to por ele, pela mulher e } \\
\text { pela filha de nove meses. }\end{array}$ & $\begin{array}{l}\text { Agregado familiar com- } \\
\text { posto por ela, pelo marido } \\
\text { e pelos dois filhos gé- }\end{array}$ & $\begin{array}{l}\text { Agregado familiar com- } \\
\text { posto por ela, pelo marido } \\
\text { e pela filha (um ano). }\end{array}$ \\
\hline $\begin{array}{l}\text { Agregado familiar composto } \\
\text { por ele e pela filha (um ano). } \\
\text { Tempo com a criança varia } \\
\text { consoante a disponibilidade. }\end{array}$ & $\begin{array}{l}\text { Tempo com a criança, desde } \\
\text { chega a casa do trabalho } \\
\text { até à hora de deitar. }\end{array}$ & $\begin{array}{l}\text { meos, de quatro anos. } \\
\text { Tempo com a criança: } \\
\text { das } 18 \mathrm{~h} \text { até à hora de } \\
\text { deitar }(21 \mathrm{~h} / 21 \mathrm{~h} 30) \text {. }\end{array}$ & $\begin{array}{l}\text { Tempo com a criança: sem- } \\
\text { pre que não está a trabalhar. }\end{array}$ \\
\hline
\end{tabular}

Tabela 3: Caracterização dos pais/mães de Vila Pouca de Aguiar e de Lisboa

As crianças dos grupos focais e os pais/mães entrevistados não têm qualquer grau de parentesco entre si. Era importante ter acesso às experiências com ecrãs vividas por crianças mais novas (até aos três anos) e isso foi possível através dos progenitores/as. Por outro lado, esta opção permitiu aumentar, ainda que indiretamente, as experiências de usos de ecrãs por crianças e de experiências de mediação parental, pelas perceções cruzadas das crianças e pais/mães participantes do estudo.

Esta investigação tem um cariz exploratório, pelo que não permite generalizar, a partir dos "casos" de crianças e de pais/mães de Lisboa e de V.P.A., para todas as crianças e progenitores/as desses contextos.

\section{RESULTADOS}

\section{O ENTRETENIMENTO INFANTIL NO TEMPO LIVRE DAS CRIANÇAS EM ESTUDO}

Olhando para a informação contextual das crianças constata-se que a maioria das 10 crianças de V.P.A. passa mais tempo livre, pois regressam a casa quando terminam a escola, enquanto oito das 10 crianças de Lisboa seguem para atividades extracurriculares (Tabelas 1 e 2, respetivamente). Num estudo sobre uso de ecrãs na esfera doméstica a diferença de tempo disponível das crianças em casa, durante a semana, tem de ser considerada.

As brincadeiras tradicionais estão presentes na vida destas crianças, mas as de Lisboa referiram mais atividades coletivas, (jogar às cartas, jogar à bola e aos balões, jogar às escondidas, à apanhada) referindo muitas vezes os "manos/as", enquanto as de V.P.A. salientaram mais atividades individuais (construção de legos, brincar com acessórios de super-heróis, com carrinhos, às mães, etc.). Esta diferença pode derivar dos meninos/as de V.P.A. serem maioritariamente filhos/as únicos/as. Em ambos os grupos percebeu-se preferências por brinquedos tradicionalmente associados a um determinado género: os meninos referiram carros, bolas e super-heróis e as meninas bonecas, peluches e unicórnios.

No âmbito dos ecrãs, a televisão foi referida por todas as crianças, e todas com ligação à internet. Os canais da TV Cabo foram privilegiados, ainda que as crianças de 
V.P.A. só referissem o Canal Panda, manifestando desconhecer o nome de outros canais que também assistem. Os grupos de Lisboa identificaram com facilidade o que viam no Disney Channel, Cartoon Network, Disney Júnior, Canal Panda e Canal Boomerang. No grupo de meninas de Lisboa também disseram que acedem à Netflix. Os conteúdos são de animação e adequados às idades. Nota-se um consumo em função do género, mais vincado nas crianças de V.P.A., podendo também estar associado à maioria ser filho/a único/a, possuindo maior autonomia na escolha. Este fator pode explicar também haver mais crianças de V.P.A., a referir que veem televisão sozinhas. Em Lisboa, também o Martim e a Amélia disseram que assistem sozinhas, sendo que ele é filho único e ela está com os irmãos mais velhos quando vai para casa do pai. Os restantes meninos/as lisboetas disseram que têm a companhia dos pais e/ou irmãos. As rotinas de uso são comuns a todas as crianças participantes: veem quando estão a arranjar-se para a escola, quando chegam da escola e antes de dormir.

Os dispositivos digitais não foram imediatamente apontados nesta fase da sessão. Apenas duas crianças de V.P.A. referiram "jogar na Nintendo" (Rodrigo) e "ver o tablet" (Miguel).

\begin{tabular}{|c|c|c|c|c|}
\hline \multicolumn{5}{|c|}{ Vila Pouca de Aguiar } \\
\hline & $\begin{array}{l}\text { O que fazem } \\
\text { depois da escola }\end{array}$ & Brinquedo/brincadeira preferido/a & $\begin{array}{l}\text { Conteúdos } \\
\text { televisivos }\end{array}$ & $\begin{array}{l}\text { Com quem } \\
\text { vêm os ecrãs }\end{array}$ \\
\hline “Pedro" & $\begin{array}{l}\text { Brinca na rua com } \\
\text { carrinhos e máquinas }\end{array}$ & - & $\begin{array}{l}\text { Desenhos } \\
\text { animados }\end{array}$ & Com os pais \\
\hline “Tiago” & $\begin{array}{l}\text { Vê televisão e } \\
\text { brinca com carros }\end{array}$ & Jogar à apanhada & $\begin{array}{l}\text { Desenhos } \\
\text { animados }\end{array}$ & $\begin{array}{l}\text { Sozinho e } \\
\text { acompanhado }\end{array}$ \\
\hline “Rodrigo" & $\begin{array}{l}\text { Jogar Super Mário } \\
\text { (Nintendo) }\end{array}$ & $\begin{array}{l}\text { Bonecos de super-heróis } \\
\text { (Hulk); jogar à apanhada }\end{array}$ & $\begin{array}{l}\text { Mikey; } \\
\text { super-heróis }\end{array}$ & $\begin{array}{l}\text { Quase sem- } \\
\text { pre sozinho }\end{array}$ \\
\hline “José” & Brinca com legos & Carrinhos & Super-heróis & $\begin{array}{l}\text { Sozinho e } \\
\text { acompanhado }\end{array}$ \\
\hline “Miguel” & $\begin{array}{l}\text { Vê televisão, brinca } \\
\text { e joga no tablet }\end{array}$ & $\begin{array}{l}\text { Mascarar-se do Homem Aranha; } \\
\text { jogos de super-heróis e Fortnite }\end{array}$ & Homem-Aranha & Com os pais \\
\hline “Beatriz" & $\begin{array}{l}\text { Lancha com a mãe; } \\
\text { vai ao taekwondo; vê } \\
\text { bonecos na televisão }\end{array}$ & $\begin{array}{l}\text { Bonecas; brincar ao "machado" } \\
\text { (jogo que fazem no recreio) }\end{array}$ & A porquinha Peppa & Com a mãe \\
\hline “Cláudia" & $\begin{array}{l}\text { Brinca com bone- } \\
\text { cas; vê televisão }\end{array}$ & $\begin{array}{l}\text { "Eu gosto mais de brincar às escondidas. } \\
\text { Mas de brinquedos é também bonecas } \\
\text { que gosto mais"; macaquinho do chinês }\end{array}$ & Rapunzel & Sozinha \\
\hline "Benedita" & $\begin{array}{l}\text { Brinca com a irmã } \\
\text { às bonecas }\end{array}$ & $\begin{array}{l}\text { "Peluche de unicórnio"; brin- } \\
\text { car "às corridas" }\end{array}$ & Minnie & $\begin{array}{l}\text { "Com a minha } \\
\text { mana, mas não } \\
\text { com os pais" }\end{array}$ \\
\hline “Gabriela” & $\begin{array}{l}\text { Brinca no parque; } \\
\text { vai ao taekwondo; } \\
\text { brinca com o pai }\end{array}$ & Bonecas; brincar "às mães e aos pais" & Minnie & $\begin{array}{l}\text { "Com o meu } \\
\text { mano" }\end{array}$ \\
\hline “Inês Leonor" & $\begin{array}{l}\text { Vai ao karaté; brinca } \\
\text { com bonecas }\end{array}$ & $\begin{array}{l}\text { "Eu gosto de brincar também com } \\
\text { um unicórnio gigante que o pai na- } \\
\text { tal me deu"; brincar às casinhas }\end{array}$ & Mickey Mouse & Sozinha \\
\hline
\end{tabular}




\begin{tabular}{|c|c|c|c|c|}
\hline \multicolumn{5}{|c|}{ LISBOA } \\
\hline & $\begin{array}{l}\text { O que fazem } \\
\text { depois da escola }\end{array}$ & Brinquedo/brincadeira preferido/a & Conteúdos televisivos & $\begin{array}{l}\text { Com quem } \\
\text { veem os ecrãs }\end{array}$ \\
\hline “Martim" & Ver televisão & Bolas saltitonas; jogar ao palhaço assassino & Titio Avô & Sozinho \\
\hline “Lucas” & Jogar à bola & $\begin{array}{l}\text { "As minhas chuteiras"; jogar às escon- } \\
\text { didas, à apanhada e à cabra cega }\end{array}$ & Bingo Rolly. & Pais e irmã \\
\hline "Afonso" & $\begin{array}{l}\text { Jogar à bola; } \\
\text { ver televisão }\end{array}$ & "As minhas bolas de futebol"; jogar futebol & $\begin{array}{l}\text { "Eu não sei o nome, } \\
\text { mas também vejo } \\
\text { aquele dos dragões" }\end{array}$ & Acompanhado \\
\hline “Carolina” & Ir ao parque & Urso de peluche; brincar à apanhada & Sunny Day & Com o irmão \\
\hline “Amélia” & Ir ao parque & Unicórnios; macaquinho do chinês & Power Rangers & Sozinha \\
\hline "Sofia" & $\begin{array}{l}\text { Ir ao parque; an- } \\
\text { dar de bicicleta }\end{array}$ & $\begin{array}{l}\text { Boneco Mickey; jogar às escondidas; } \\
\text { pintar livros; brincar às mães e aos pais }\end{array}$ & $\mathrm{H}_{2} \mathrm{O}$ & Com as irmãs \\
\hline "Violeta" & $\begin{array}{l}\text { Andar com } \\
\text { a mãe }\end{array}$ & $\begin{array}{l}\text { Peluches e "bebés"; "nós às vezes } \\
\text { não brincamos a nada, andamos pelo } \\
\text { recreio a conversar e assim..." }\end{array}$ & Tom QJerry & Com a mãe \\
\hline
\end{tabular}

Tabela 5: O entretenimento das crianças de Lisboa no espaço doméstico

\section{O CONSUMO DE ECRÃS E REGRAS DE UTILIZAÇÃo NA PERSPETIVA DAS CRIANÇAS}

Todas as crianças do estudo disseram que os seus lares estão equipados com (pelo menos uma) televisão e telemóveis. O tópico "tablet" foi recebido com grande entusiasmo em todas as sessões, mas notou-se uma discrepância na posse e/ou acesso entre os grupos de V.P.A e os de Lisboa - oito das 10 crianças de V.P.A. têm e/ou utilizam tablets e, dessas, cinco têm um só para si. Nos grupos de Lisboa apenas cinco das 10 crianças têm acesso a este dispositivo e, na sua maioria, provêm dos pais ou dos irmãos) (Tabelas 6 e 7$)$.

Os conteúdos privilegiados pela maioria das crianças de V.P.A. e de Lisboa quando utilizam os ecrãs portáteis são vídeos de animação e do youtuber Lucas Neto. Cinco crianças transmontanas, na maioria meninos, disseram que também jogam no telemóvel e no tablet. No grupo de Lisboa, apenas o Martim disse que também joga. A utilização destes dispositivos, em ambos os espaços, ocorre essencialmente nos lares, com algumas exceções (casa dos avós, quando vão ao restaurante e quando viajam de carro).

Em termos de perceção de regras, as crianças dos grupos focais de V.P.A. denotaram perceber uma menor regulação na utilização. Só o Miguel referiu que a mãe the impôs uma limitação de tempo por estar a ficar viciado - "só posso usar meia hora à noite (...) e meia hora quando chego da escola". A Beatriz e a Gabriela de V.P.A. abordaram restrições de (um mesmo) conteúdo por "ser assustador". As restantes crianças 
dizem que podem ver sempre que querem. Já as dos grupos lisboetas há várias a dizer que estão dependentes da autorização do pai/mãe.

\begin{tabular}{|c|c|c|c|c|}
\hline \multicolumn{5}{|c|}{ Vila Pouca de Aguiar } \\
\hline & $\begin{array}{l}\text { De quem é o tablet/ } \\
\text { telemóvel }\end{array}$ & $\begin{array}{l}\text { O que fazem nos } \\
\text { tablets/telemóveis }\end{array}$ & $\begin{array}{l}\text { Onde usam os tablets/ } \\
\text { telemóveis }\end{array}$ & $\begin{array}{l}\text { Regras de utiliza- } \\
\text { ção dos ecrãs }\end{array}$ \\
\hline “Tiago" & $\begin{array}{l}\text { "Eu tenho um tablet } \\
\text { velho e um tablet novo. } \\
\text { Tenho dois meus" }\end{array}$ & Jogos ("crocodilo") & $\begin{array}{l}\text { Em casa e "quando vou } \\
\text { comer ao restauran- } \\
\text { te com o meu pai" }\end{array}$ & Não tem \\
\hline "Rodrigo" & "Eu tenho um tablet" & Ver vídeos (Gato Galático) & Só em casa & Não tem \\
\hline “José" & - & $\begin{array}{l}\text { Ver vídeos (Super Mário, } \\
\text { Lucas Neto e Mickey); } \\
\text { jogos ("diamantes") }\end{array}$ & - & Não tem \\
\hline “Miguel” & "O tablet é só meu" & $\begin{array}{l}\text { Ver vídeos (Lucas Neto, } \\
\text { MineCraft e Homem } \\
\text { Aranha); jogos (Minecraft) }\end{array}$ & Em casa e na casa da avó & $\begin{array}{l}\text { "A minha pôs } \\
\text { porque ela disse } \\
\text { que eu estava } \\
\text { muito viciado" }\end{array}$ \\
\hline “Beatriz" & $\begin{array}{l}\text { "Eu não tenho tablet, } \\
\text { nem a minha mãe" }\end{array}$ & Lucas Neto & - & $\begin{array}{l}\text { "Eu posso ver } \\
\text { todos os dias" }\end{array}$ \\
\hline “Cláudia" & $\begin{array}{l}\text { "Eu tenho um tablet } \\
\text { que é da mãe" }\end{array}$ & $\begin{array}{l}\text { "Eu faço jogos no tablet. } \\
\text { Mas não vejo vídeos" }\end{array}$ & Em casa & $\begin{array}{l}\text { "Eu não te- } \\
\text { nho regras" }\end{array}$ \\
\hline “Benedita” & $\begin{array}{l}\text { "O tablet é da mi- } \\
\text { nha mana" }\end{array}$ & $\begin{array}{l}\text { Desenhos animados: } \\
\text { A porquinha Peppa e } \\
\text { princesas; jogos }\end{array}$ & Em casa e na casa dos avós & $\begin{array}{l}\text { "Eu posso ver } \\
\text { todos os dias" }\end{array}$ \\
\hline “Gabriela" & $\begin{array}{l}\text { "O meu computador é só } \\
\text { do meu mano e meu" }\end{array}$ & $\begin{array}{l}\text { Lucas Neto; "eu vejo } \\
\text { um jogo de animais" }\end{array}$ & - & - \\
\hline
\end{tabular}

Tabela 6: Posse e utilização de ecrãs digitais pelas crianças de Vila Pouca de Aguiar e respetiva regulação parental

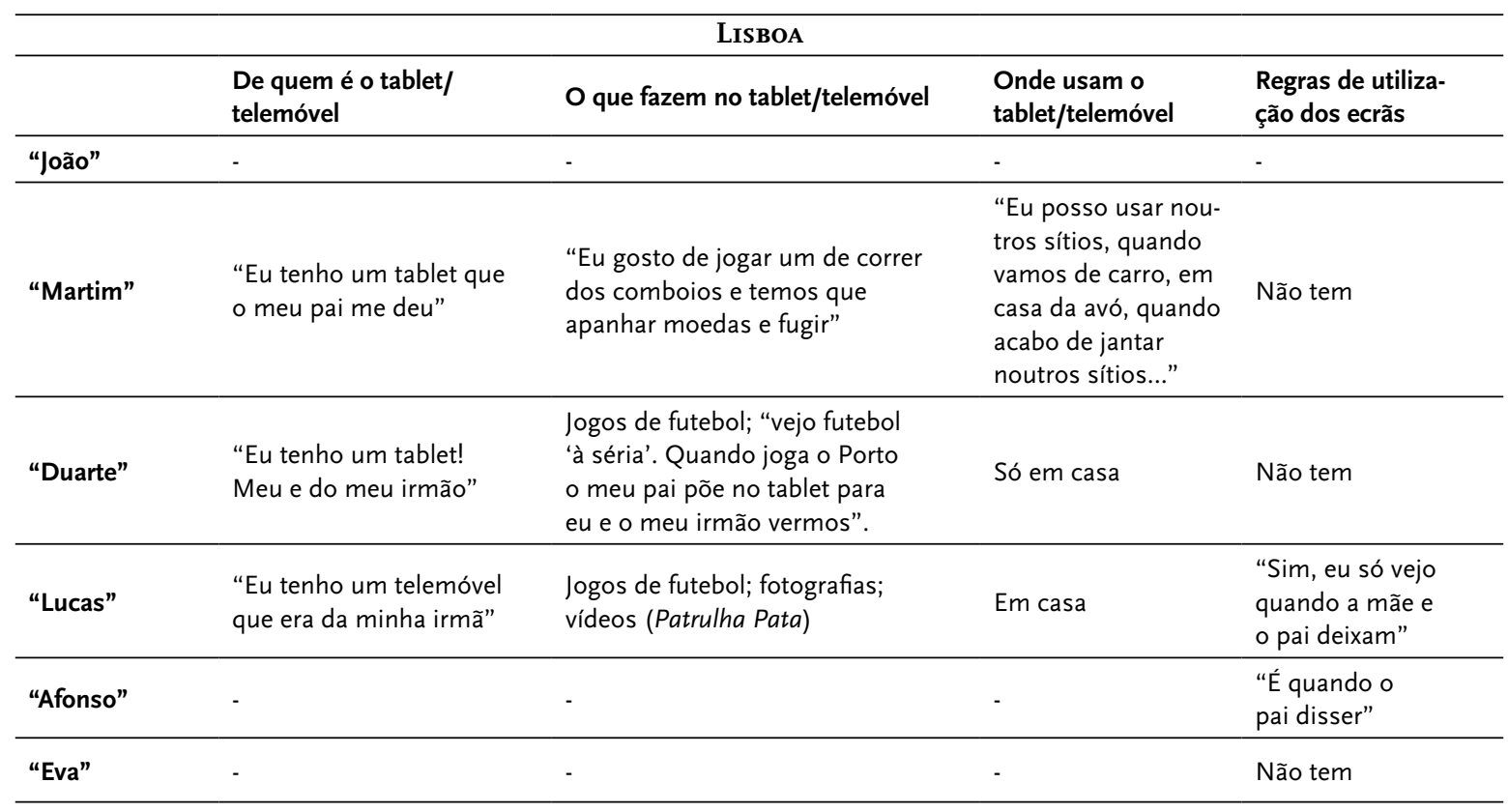




\begin{tabular}{|c|c|c|c|c|}
\hline “Carolina" & - & - & - & $\begin{array}{l}\text { "Quando os pais } \\
\text { deixam. Eu peço } \\
\text { e eles dizem se } \\
\text { eu posso ou se } \\
\text { não posso" }\end{array}$ \\
\hline "Amélia" & $\begin{array}{l}\text { "Eu tive três! (..) Um } \\
\text { está em casa da mãe e } \\
\text { outro está em casa do } \\
\text { pai. E tenho um telemóvel } \\
\text { que era da mãe e agora } \\
\text { estragou-se e eu vejo nele" }\end{array}$ & $\begin{array}{l}\text { "Eu vejo o YouTube mais vezes. } \\
\text { Vejo o Lucas Neto, os irmãos } \\
\text { Neto, uns bonecos, a Patrulha } \\
\text { Pata, vejo muitas coisas..." }\end{array}$ & Em casa & $\begin{array}{l}\text { "A minha mãe diz } \\
\text { para eu não mexer } \\
\text { no comando. Eu } \\
\text { tenho que pedir e } \\
\text { ela deixa. No meu } \\
\text { tablet eu posso ver, } \\
\text { tenho só que avisar" }\end{array}$ \\
\hline "Sofia" & - & - & - & Não tem \\
\hline “Violeta" & $\begin{array}{l}\text { "Eu tenho um tablet que } \\
\text { me deu o pai Natal" }\end{array}$ & $\begin{array}{l}\text { "Vejo mais desenhos animados. } \\
\text { O Bingo e Roli, a Patrulha Pata..." }\end{array}$ & Em casa & Não tem \\
\hline
\end{tabular}

Tabela 7: Posse e utilização de ecrãs digitais pelas crianças de Lisboa e respetiva regulação parental

Apesar de terem quatro e cinco anos, duas crianças transmontanas relataram habilidades com os ecrãs digitais que lhes dão independência na exposição e no consumo de conteúdos. É o caso do Miguel (cinco anos): “às vezes instalo jogos. Mas já desinstalei porque era uma asneira"; e do Rodrigo: "eu pus jogos no telemóvel da mãe e sou eu que jogo o Super Mário".

\section{PARTICIPAÇÃo E RESPONSABILIDAdeS dos PAis/MÃes NO CONSUMO de ECRÃS PELOS FilhoS}

Nas entrevistas aos progenitores/as procurou conhecer-se, para cada um dos contextos, os hábitos de consumo de ecrãs, em casa, por parte dos filhos, e compreender o exercício de mediação desenvolvido.

Os oito elementos que compunham o painel de entrevistados (V.P.A. e Lisboa) referiram ter lares tecnológicos: (pelo menos) um televisor, tablets e telemóveis. Três progenitores de Lisboa têm computadores, bem como o pai António de V.P.A. (jardineiro, de 37 anos) que refere, ainda, a posse de uma PlayStation. De uma forma geral, os filhos/as preferem os ecrãs digitais, especialmente o tablet, e três dos pais do painel de V.P.A. disseram que os filhos (de três e quatro anos) têm esse dispositivo só para si. A televisão, nas palavras dos pais/mães de V.P.A. parece estar a perder o interesse para os seus filhos (até aos três anos). Um pai e uma mãe de V.P.A. mencionaram que os filhos "já não assistem de todo" (pai António e mãe Madalena). Os restantes dizem que o que veem são desenhos animados. Já entre os progenitores/as de Lisboa notou-se que, apesar dos seus filhos/as preferirem também os ecrãs digitais, utilizam-nos de forma mais regrada e acompanhada (por eles/as ou dos irmãos mais velhos).

De acordo com a generalidade dos pais/mães, os filhos/as preferem os ecrãs digitais por serem mais estimulantes, pela facilidade de transporte e por permitirem maior autonomia na utilização. O pai Pedro (Lisboa), a respeito da sua filha de um ano, disse "ela não gosta de estar parada (...) de estar sentada a olhar para o ecrã (...) ela vai acabar 
por gostar mais do telemóvel, porque está sempre a pedir". Também o pai António (V.P.A.) diz que o filho de três anos não gosta de ver televisão por ser "um ecrã mais difícil de o 'agarrar'”. O pai Miguel (Lisboa), sobre a sua bebé de nove meses, afirma: "desde que lhe desperte a curiosidade ou the chame a atenção, ela gosta. Mas pede mais vezes o telemóvel e o tablet, talvez por serem mais pequenos e estarem mais perto". Para a mãe Marta (Lisboa) serem eles a escolher o conteúdo faz com que gostem do tablet: "eles estão mais habituados a ver televisão, mas é muito mais dinâmico um tablet (...) para poderem escolher eles".

Quanto à idade que os filhos/as começaram a usar os ecrãs digitais, dois pais de Lisboa referiram idades inferiores a um ano (pai Miguel e mãe Vera), através dos seus telemóveis. Os pais/mães de V.P.A. apontaram um ano e meio/dois. Porém, os pais mais restritivos pertencem ao painel de Lisboa: a mãe Marta disse que os seus gémeos de quatro anos acederam a esses ecrãs já muito próximo da idade que têm e até se aconselhou com a pediatra; e o pai Pedro não deixa ainda a filha de um ano aceder, ainda que ela esteja sempre a pedir. Mas, na generalidade, os pais/mães, acreditam não existir uma idade específica para começar a utilizar/oferecer estes ecrãs.

Para a maioria dos pais/mães, a pressão de "todos terem" condicionou que facilitassem o acesso. A mãe Marta (Lisboa) referiu: "os pais também têm telemóveis e eles crescem com ecrãs (...) esta geração já nasce mesmo para isto, é quase impossível proibir". Os irmãos ou primos mais velhos também influenciam o primeiro contacto e uma eventual compra, pois despertam mais cedo para a visualização dos diferentes ecrãs (como referiram o pai António e as mães Madalena e Judite, de V.P.A).

No acompanhamento parental na utilização de ecrãs as respostas dos pais de V.P.A. variaram: os pais António e Carlos, ambos com filhos de três anos, disseram "às vezes sim, mas nem sempre!". Estes pais assumiram que os filhos veem o tablet sem grande restrição ou supervisão. A mãe Madalena diz que o filho de três anos pode ver livremente, mas "no mesmo espaço que nós, enquanto vemos televisão" e a mãe Judite também conta com a ajuda da filha mais velha. No painel de Lisboa o pai Pedro foi quem se mostrou mais restritivo. A filha de um ano só vê televisão, no canal de música que ele escolhe, e sempre na sua presença. O pai Miguel (filha de nove meses) disse que "televisão até vê sozinha, mas o tablet vê comigo ou com a mãe, pois temos medo que ela estrague o equipamento". As mães Marta (gémeos de quatro anos) e Vera (filha de um ano e nove meses) restringem os diferentes ecrãs da casa e o tempo de contacto (televisão todos os dias e ecrãs digitais só aos fins-de-semana) e, a mãe Marta pré-definiu os vídeos a que podem aceder e vai "deitando o olho" enquanto está na cozinha. Notou-se, em ambos os contextos, que o acompanhamento vai diminuindo à medida que a idade aumenta ou quando têm irmãos mais velhos.

Das atividades realizadas nos ecrãs digitais, registou-se jogar, ver vídeos de animação e do youtuber Lucas Neto e música. O Pai António (V.P.A.), o mais permissivo de todos os progenitores deste estudo, e o que passa menos tempo com o filho diariamente, disse que o filho de três anos vê muito o Lucas Neto e "eu até acho bom para ele, porque ensina coisas boas, como poupar água, separar o lixo, arrumar os brinquedos depois de 
os usar, não gozar com os colegas, não ser invejoso... coisas assim!". O pai Pedro (Lisboa) refere que o tablet até pode ser interessante em termos de estímulo cognitivo: "não os jogos normais que eles tendem a gostar, mas outros tipos de jogos como montar peças... pode ajudar a desenvolver raciocínio espacial e isso é importante".

Quer em Lisboa, como em V.P.A. os progenitores/as referem uma utilização instrumental dos ecrãs e essencialmente em casa, com algumas exceções: "no carro" (pai Carlos, V.P.A.); "se formos a algum restaurante às vezes também levam para que no fim da refeição não se aborreça" (mãe Madalena, V.P.A.); "quando vamos aos meus sogros, ao fim de semanal depois de almoço, enquanto estamos ali ainda a conversar e eles estão um bocadinho fartos" (mãe Marta, Lisboa).

A principal preocupação dos pais/mães, sejam de Lisboa ou de V.P.A., é o perigo de encontrarem "coisas" que não entendam. Mas manifestaram que a preocupação irá aumentar quando os filhos forem mais velhos, tal como acontece com alguns que têm fiIhos adolescentes. Para já a apreensão "é com a visão, as dores de cabeça" (pai António, V.P.A.), "o ciclo de sono e o tempo de uso" (mãe Madalena, V.P.A.) que, diz, irá controlar mais, quando a criança tiver responsabilidades escolares e que o uso da tecnologia possa influenciar a "interação social" (pai Miguel, Lisboa). A mãe Marta (Lisboa) receia "que seja muito viciante". (...) A minha grande preocupação é dar-lhes outras opções, para que eles também cresçam a brincar com outros tipos de brinquedos". O pai Pedro (Lisboa) diz que irá fomentar essencialmente conteúdos pedagógicos que possam trazer benefícios cognitivos e com tempo controlado, pois quanto mais tempo usam mais suscetíveis ficam de encontrar conteúdos impróprios para a idade e para aquilo que possam compreender.

\section{DisCUSSÃo}

A variável urbanidade/ruralidade das residências das crianças e dos progenitores/ as participantes não influenciou a presença de equipamento tecnológico dos lares, corroborando com as conclusões de Plowman et al. (2010) e os estudos de outros espaços europeus (Ofcom, 2019). Também não foi afetada pela condição socioeconómica mais desfavorecida de alguns lares de progenitores/as de V.P.A., confirmando a conclusão de Dias e Brito (2018) de que as crianças vivem em ambientes digitais ricos, mesmo quando integram famílias economicamente desfavorecidas.

Contudo, as residentes em V.P.A. manifestaram um maior contacto com os diversos ecrãs da casa e uma utilização mais dinâmica e autónoma com o tablet e telemóveis, contrariando o estudo de Kabali et al. (2015) que atribuem aos meios citadinos uma maior utilização. Isso poderá estar relacionado com o tempo que passam em casa, pois cruzando com as rotinas após a escola, percebe-se que a maioria dos grupos de crianças lisboetas referiram ter atividades extracurriculares. E crianças com mais tempo dentro de lares tecnológicos poderão preencher a "sua agenda" com entretenimento eletrónico e digital (Ponte et al., 2017).

A composição do agregado também pode justificar consumos diferenciados de media em casa. A generalidade das crianças participantes de Lisboa têm irmãos, com 
quem interagem nas brincadeiras e no consumo dos ecrãs. Nevski e Siibak (2016) já tinham evidenciado o impacto dos irmãos na orientação do consumo dos mais novos. Já as crianças de V.P.A., maioritariamente filhos/as únicos/as, manifestaram um consumo mais solitários de ecrãs. Jorge, Tomé e Pacheco (2017) referem que em contextos familiares monoparentais e de filhos únicos, as crianças tendem a ser delegadas ao "babysitting digital" (Leskova, Jurjewicz, Lenghart \& Bacik, 2018).

Neste estudo, verificou-se que as crianças de quatro e cinco anos e os filhos com menos de três anos dos pais/mães entrevistados de V.P.A. usam mais os pequenos ecrãs, sobretudo o tablet, que aquelas de Lisboa. Cardoso, Vieira e Mendonça (2016) dizem que os ecrãs mais pequenos, portáteis e tácteis permitem que as crianças se sintam mais envolvidas e com mais poder de decisão para fazerem "o controlo da sua dieta de media" (p. 35). Nikolopoulou (2020) considera natural que a criança com idade pré-escolar, ainda com pouca motricidade fina, sinta maior atração pelos tablets por exigirem apenas o uso do dedo.

Em termos de mediação parental, as crianças de V.P.A. transmitiram menos consciência de regras de utilização de ecrãs. Apenas o Miguel evidenciou uma restrição de tempo por estar "muito viciado". Já a maioria das crianças de Lisboa mostraram alguma consciência da intervenção parental, pois muitos disseram que estão dependentes da sua autorização para usarem ecrãs. Mas neste estudo identificou-se essencialmente a mediação restritiva (e.g. Livingstone et al., 2015).

Todos os pais/mães do painel de entrevistados foram ou são os "patrocinadores" diretos do uso tecnológico dos seus filhos (Kabali et al., 2015). O pai de uma bebé de nove meses (V.P.A.), disse que a filha começou a usar o smartphone e o tablet desde que se "se começou a mexer", congruente com as descobertas de Cardoso et al. (2015). $\mathrm{O}$ acesso derivou de um presente de aniversário (família do Pai António de V.P.A.) ou da passagem geracional dos dispositivos à medida que os pais/mães ou irmãos mais velhos vão fazendo as atualizações (sobretudo as crianças e os pais/mães dos grupos de Lisboa).

Entre os pais/mães de Lisboa e de V.P.A. encontraram-se diferenças, mas não se tornou claro se se devem a uma questão geográfica ou socioeconómica (formação académica e profissão), como demonstrado por Clark (2013). A mãe de V.P.A. com formação superior (Madalena, professora) foi a única que instituiu algumas regras de uso de ecrãs à filha de três anos (e outro de oito): "veem quando chegam da escola, ao fim da tarde, mas depois de jantar não dou. (...) E quando começam a ver coisas que não autorizo, tiro-lhes". Já os restantes pais/mães de V.P.A. não desenvolvem uma mediação efetiva - os filhos "podem ver à noite, enquanto jantam, quando acordam, quando estão a lanchar e quando se vão deitar", denotando um estilo de parentalidade passiva ou laissez-faire (Baumrind, 1991) e um sentimento de que não têm capacidades suficientes para ajudar os/as filhos/as (Nevski \& Siibak, 2016; Nikken \& de Haan, 2015).

Os progenitores/as de Lisboa são todos licenciados, apesar de dois exercerem profissões que não exigem tal formação (carteiro e auxiliar de educação). O pai com regras mais restritivas é de Lisboa (Pai Pedro) e tem formação e profissão mais qualificadas: 
"ela já pediu várias vezes para usar mas eu não deixo. Ela de vez em quando tira-me o telemóvel e eu vou atrás dela e tiro-lho. Não costumo deixar em nenhuma situação". Mas assume que mais tarde a deixará usar o tablet, pois quando bem utilizado (Domoff et al., 2019) "pode ser interessante para ela em termos de estímulo". Este pai, usuário competente de tecnologia, estabelece nesta fase da vida da filha de um ano estratégias de parentalidade rigorosa (Baumrind, 1991). Outros remetem para estratégias de acompanhamento mais próximo "estou sempre eu ou a mãe, mas muitas vezes estamos todos" (Pai Miguel) ou de supervisão à distância ("vou deitando um "olho") ou mediação técnica, pré-definindo os conteúdos (mãe Marta) (e.g. Livingstone \& Helsper, 2008; Nikken \& Jansz, 2014; Nikken \& Schols, 2015).

Todos os pais/mães admitiram maior preocupação quando os filhos crescerem. Por enquanto consideram que "controlam", manifestando mais apreensão com eventuais problemas de visão ou dores de cabeça (pai António, V.P.A.), com a interrupção do ciclo de sono (mãe Judite, V.P.A.) devido ao tempo de exposição dos filhos aos dispositivos. O pai Miguel (Lisboa) receia os problemas de interação social e com o meio envolvente que a filha possa ter e a mãe Marta (Lisboa) que o filho se desinteresse por outras atividades. Temores já enumerados nos estudos de Gottschalk (2019), de Kardefelt-Winther (2017) e de Twenge e Campbell (2018).

\section{SÍNTESE FINAL}

Independentemente da geografia, os lares dos sujeitos integrantes deste estudo exploratório (crianças e progenitores/as) estão rodeados de tecnologia com ligação à internet, sendo os pequenos ecrãs digitais os mais apetecíveis para todas as crianças menores de cinco anos. Mas as crianças residentes em V.P.A. referiram maior exposição a esses dispositivos, especialmente aos tablets, face aos grupos de Lisboa. Da mesma forma, algumas crianças transmontanas relataram experiências de jogos digitais e maior competências e autonomia para fazerem downloads destas aplicações nos telemóveis dos pais. Levanta-se a hipótese teórica de poder não ser apenas a variável urbanidade/ ruralidade a gerar esta diferença, mas estar associada às crianças de V.P.A. terem mais tempo livre em casa, após a escola e, na sua maioria, serem filhos/as únicos/as e, portanto, mais focados em brincadeiras tradicionais e/ou consumo de ecrãs individualizados.

Os conteúdos mais consumidos são os programas de animação nos principais canais infantis de televisão por cabo bem como no YouTube, onde também seguem um youtuber da moda (Lucas Neto). Porém, as crianças de Lisboa demonstraram maior conhecimento sobre os canais televisivos que conectam, sendo coerente com o facto de verem mais TV durante a semana em detrimento dos ecrãs digitais. Muitas crianças de V.P.A. utilizam os ecrãs sozinhas e possuem uma menor consciência de regras de uso e/ou de conteúdos por parte dos seus progenitores, contrastando com os grupos de crianças lisboetas que referiram, na generalidade, ver televisão e ecrãs digitais acompanhadas pelos pais ou irmãos e relataram condutas de mediação mais claras por parte dos pais. Todas as crianças do estudo que usam ecrãs digitais portáteis assumiram que os veem essencialmente em casa e de forma instrumental (quando se estão a arranjar, 
a comer ou antes de irem dormir) ainda que, excecionalmente os utilizem no carro, nos restaurantes ou nos almoços demorados de família.

Nas entrevistas semiestruturadas aos pais/mães, com crianças de meses até aos quatro anos, percebeu-se uma tendência semelhante: os seus filhos preferem o tablet ou telemóveis. Mas são também as crianças dos pais/mães de V.P.A. que tem acesso facilitado aos meios digitais, muitos deles para uso pessoal. Os pais/mães de ambos os espaços disseram que se sentem pressionados a "patrocinar" o acesso, com mais ou menos tempo de utilização, pelo receio de excluírem os filhos da geração digital a que pertencem. Todos transmitiram alguma apreensão, mas consideram que a maior preocupação virá quando forem mais velhos. Apesar disso, os pais entrevistados de V.P.A. manifestaram uma atitude menos restritiva, quer em relação ao acesso, como ao tempo de uso e aos conteúdos a que os filhos/as acedem. Em nenhum dos grupos de pais/mães dos contextos geográficos representados neste estudo se identificaram práticas de mediação ativa ou de co-uso efetivo. Os pais/mães das crianças com meses acompanham-nas durante o uso de ecrãs digitais, mas para garantirem a boa utilização dos equipamentos.

Estas tendências não podem, contudo, ser generalizadas aos contextos urbano e rural aqui retratados, pela limitação de crianças e de pais/mães participantes. Amostras mais vastas de ambos os contextos (citadino ou rural) e uma representação social mais diversificada, permitiria ilações mais extensivas sobre os efeitos que as variáveis urbanismo/ruralidade têm na exposição das crianças menores de cinco anos aos ecrãs e nas estratégias de mediação dos pais. Mas, aceder a crianças desta faixa etária exige um protocolo ético e de autorizações que dificultam o acesso e torna moroso todo o processo de pesquisa.

\section{REFERÊNCIAS}

Ariani, A., Putu, N., Aditya, R., Endriyani, N. \& Niati, R. (2017). Effects of playing gadget on elementary school children in urban and rural environment. Advances on health sciences research, 2, 22-27.

Baumrind, D. (1991). The influence of parenting style on adolescent competence and substance use. Journal of Early Adolescence, 11(1), 56-95.

Bell, V., Bishop, D. V. M. \& Przybylski, A. K. (2015). The debate over digital technology and young people. BMJ, 351, h3064. https://doi.org/10.1136/bmj.h3064

Beyens, I. \& Eggermont, S. (2014). Putting young children in front of the television: antecedents and outcomes of parents. Use of television as a nabysitter. Communication Quarterly, 62(1), 57-74.

Blum-Ross, A. \& Livingstone, S. (2018). The trouble with "screen time" rules. In G. Mascheroni; C. Ponte \& A. Jorge (Eds), Digital parenting. the challenges for families in the digital age (pp. 179-187). Goteborg: Nordicom.

Brito, R. (2018). Estilos de mediação do uso de tecnologias digitais por crianças até aos 6 anos. Da Investigação às Práticas, 8(2), 21-46.

Bryman, A. (2016). Social research methods. Oxford University Press. 
Cardoso, G., Mendonça, S., Paisana, M., Lima T. \& Neves, M. (2015). Os media e as dinâmicas geracionais na sociedade Portuguesa. Análise dos impactos das variáveis geracionais nas práticas mediáticas dos portugueses. Lisboa: OberCom.

Cardoso, G., Vieira, J. \& Mendonça, S. (2016). Ecrãs em rede. Televisão. Tendências e prospectivas. Lisboa: OberCom Investigação e saber em comunicação.

Çetintaş, H. B. \& Turan, Z. (2018). Through the eyes of early childhood students: television, tablet computers, internet and smartphones. Central European Journal of Communication, 11(1), 56-70.

Clark, L. S. (2013). The parent app: understanding families in the digital age. Oxford: Oxford University Press.

Cordeiro, M. (2015). Crianças e famílias num Portugal em mudança. Lisboa: Fundação Francisco Manuel dos Santos

Council on Communications and Media. (2013). Children, adolescents, and the media. Pediatrics, 132(5), 958-961.

Dias, P. \& Brito, R. (2018). Happy kids. Aplicações seguras e benéficas para crianças felizes. Perspetiva dos pais. Lisboa: Universidade Católica Portuguesa.

Domingues-Montanari, S. (2017). Clinical and psychological effects of excessive screen time on children. Journal of Paediatrics and Child Health, 53(4), 333-338.

Domoff, S. E., Radesky, J. S., Harrison, K., Riley, H., Lumeng, J. C. \& Miller, A. L. (2019). A naturalistic study of child and family screen media and mobile device use. Journal of Child and Family Studies, 28(2), 401-410.

Duch, H., Fisher, E.M., Ensari, I. \& Harrington, A. (2013). Screen time use in children under 3 years old: a systematic review of correlates. International Journal of Behavioral Nutrition and Physical Activity 10. Retirado de http://www.ijbnpa.org/content/10/1/102

Evans, C. A., Jordan, A. B. \& Horner, J. (2011). Only two hours? A qualitative study of the challenges parents perceive in restricting child television time. Journal of Family Issues, 32(9), 1223-1244.

Gottschalk, F. (2019) Impacts on technologies use on children: exploring literature on the brain, cognition and wellbeing. OECD Education Working Paper No. 195. https://doi.org/10.1787/19939019

Harris, L., Davis, N., Cunningham, U., de Vocht, L., Macfarlane, S., Gregory, N., Aukuso, S.,Taleni, T.O. \& Dobson, J. (2018). Exploring the opportunities and challenges of the digital world for early childhood services with vulnerable children. International Journal of Environmental Research and Public Health, 15(11), 2407. https://doi.org/10.3390/ijerph15112407

Holloway, D. J., Green, L. \& Stevenson, K. J. (2015). Digitods: toddlers, touch screens and Australian family life. Brisbane: Queensland University of Technology. Retirado de https://ro.ecu.edu.au/ ecuworkspost2013/1777

INE, Instituto Nacional de Estatísticas. (2011). Censos da População e da Habitação. Lisboa: INE.

INE, Instituto Nacional de Estatísticas. (2015). Sociedade da informação e do conhecimento - inquérito à utilização de tecnologias. Lisboa: INE.

Jorge, A., Tomé, V. \& Pacheco, R. (2017). Um dia na vida de crianças com menos de 3 anos: os meios digitais no quotidiano das famílias. In M. I. V. Lopes; N. Ribeiro; G. G. S. Castro \& C. D. Burnay (Org.), Atas do XV Congresso IBERCOM (pp. 3486- 3505). Lisboa: ASSIBERCOM.

Kabali, H., Irigoyen, M., Nunez-Davis, R., Budacki, J., Mohanty, S., Leister, K. \& Bonner, R. (2015). Exposure and use of mobile media devices by young children. Pediatrics, 136(6), 1-7. 
Kardefelt-Winther, D. (2017). How does the time children spend using digital technology impact their mental well-being, social relationships and physical activity?: an evidence-focused literature review. Florença: Unicef Office of Research-Innocenti.

Köksalan, B., Aldim, U. F. \& Göğebakan, S. (2019) Media consuming in children: child development, babyhood (o-2), early childhood, interests. In S. Gülsah \& S. Gülah (Eds). Handbook of research on children's consumption of digital media (pp. 41-59). EUA: IGI Global.

Leskova, A., Jurjewicz, H., Lenghart, P. \& Bacik, P. (2018). Current challenges of digital technologies. Communications-Scientific letters of the University of Zilina, 20(1A), 16-21.

Livingstone, S. (1998). Mediated childhoods: a comparative approach to young people's changing media environment in Europe. European journal of communication, 13(4), 435-456.

Livingstone, S. \& Byrne, J. (2018). Parenting in the digital age. The challenges of parental responsibility in comparative perspective. In G. Mascherone; C. Ponte \& A. Jorge (Eds.), Digital parenting. The challenges for families in the digital age (pp. 19-30). Goteborg: Nordicom.

Livingstone, S. \& Helsper, E. (2008). Parental mediation and children's internet use. Journal of Broadcasting Q Electronic Media, 52(4), 581-599.

Livingstone, S., Mascheroni, G., Dreier, M., Chaudron, S. \& Lagae, K. (2015). How parents of young children manage digital devices at home: the role of income, education and parental style. Londres: EU Kids Online, LSE.

Mendoza, K. (2009). Surveying parental mediation: connections, challenges and questions for media literacy. The Journal of Media Literacy Education, 1(1), 28-41.

Nathanson, A. (1999), Identifying and explaining the relationship between parental mediation and children's aggression. Communication Research, 26(2), 124-143.

Nevski, E. \& Siibak, A. (2016). Mediation practices of parents and older siblings in guiding toddlers' touchscreen technology use: an ethnographic case study. Media Education Studies Q Research, 7, 320-340.

Nikken, P. (2019). Parents' instrumental use of media in childrearing: relationships with confidence in parenting, and health and conduct problems in children. Journal of Child and Family Studies, 28(2), 537-546.

Nikken, P. \& de Haan, J. (2015). Guiding young children's internet use at home: problems that parents experience in their parental mediation and the need for parenting support. Cyberpsychology: Journal of Psychosocial Research on Cyberspace, 9(3). https://www.doi.org/10.5817/CP2015-1-3

Nikken, P. \& Jansz, J. (2014). Developing scales to measure parental mediation of young children's internet use. Learning, Media and Technology, 39(2), 250-266.

Nikken, P. \& Schols, M. (2015). How and why parents guide the media use of young children. Journal of Child and family Studies, 24(11), 3423-3435.

Nikolopoulou, K. (2020). Preschool children's use of tablet at home and parents' views. In S. Papadakis \& M. Kalogiannakis (Eds.), Mobile learning applications in early childhood education (pp. 209-229). Hershey: IGI Global.

Nomaguchi, K. M. (2009). Change in work-family conflict among employed parents between 1977 and 1999. Journal of Marriage and Family, 71(1), 15-32. 
Ofcom, The Office of Communications. (2019). Children and parents: media use and attitudes report. Londres: Office of Communications.

Patraquim, C., Ferreira, S., Martins, H., Mourão, H., Gomes, P. \& Martins, S. (2018). As crianças e a exposição aos media. Nascer e Crescer, 27(1), 11-21.

Paudel, S., Jancey, J., Subedi, N. \& Leavy, J. (2017). Correlates of mobile screen media use among children aged o-8: a systematic review. BMJ Open, 7(10), 1-12.

Plowman L, McPake, J. \& Stephen, C. (2010). The technologisation of childhood? Young children and technology in the home. Children and Society, 24(1), 63-74.

Ponte, C. \& Vieira, N. (2008). Crianças e internet, riscos e oportunidades. Um desafio para a agenda de pesquisa nacional. In M. L. Martins \& M. Pinto (Eds.), Comunicação e Cidadania. Actas do $5^{\circ}$ Congresso da SOPCOM (pp. 2732-2741). Braga: CECS.

Ponte, C., Simões, J., Batista, S. Castro, T. \& Jorge, A. (2017). Crescendo entre ecrãs. Usos dos média por crianças de 3 a 8 anos - relatório final. Lisboa: ERC - Entidade Reguladora para a Comunicação Social.

Prensky, M. (2001). Digital natives, digital immigrants. On the Horizon, 9(5), 1-6.

Przybylski, A. K. \& Weinstein, N. (2019). Digital screen time limits and young children's psychological wellbeing: evidence from a population-based study. Child Development, go(1), 56-65.

Twenge, J. M. \& Campbell, W. K. (2018). Associations between screen time and lower psychological well-being among children and adolescents: evidence from a population-based study. Preventive Medicine Reports, $12,271-283$.

Weber, S. \& Mitchell, C. (2008). Imaging, keybording, and posting identities: young people and new media technologies. Youth, Identity, and Digital Media, 25-48.

\section{NOTAS BIOGRÁFICAS}

Carla Cruz é doutorada em Ciências da Comunicação, na especialidade de Sociologia da Comunicação, Mestre em Sociologia, e Licenciada em Comunicação Social. É Professora Auxiliar no Instituto Superior de Ciências Sociais e Políticas da Universidade de Lisboa, lecionando nas áreas científicas de Ciências da Comunicação $\left(1^{\circ}, 2^{\circ}\right.$ e $3^{\circ} \mathrm{Ci}$ clos) e de Sociologia ( $1^{\circ}$ e $2^{\circ}$ Ciclos). É investigadora no Centro de Investigação de Políticas Públicas (CAPP), onde coordena o projeto "Representações mediáticas de públicos sensíveis". Internacionalmente ela integra a equipa de um projeto da EUPRERA. É ainda vice-presidente do Observatório da Criança, Associação '100 Violência'.

ORCID: https://orcid.org/0000-0003-0523-0350

Email: ccruz@iscsp.ulisboa.pt

Morada: Rua Almerindo Lessa, 1300-666 Lisboa, Portugal

Catarina Franco é licenciada em Ciências da Comunicação pelo Instituto de Ciências Sociais e Políticas (ISCSP) da Universidade de Lisboa. Profissionalmente, tem colaborado em vários programas de televisão, através da Produtora de Televisão Shine Iberia: foi logger para o programa da TVI Pesadelo na cozinha 2019 e fez parte da equipa 
de produção de conteúdos do programa The voice Portugal 2019 e do programa infantil $A$ árvore dos desejos 2020. E desde 2015 que é monitora de crianças e jovens (dos 4 aos 16 anos), em campos de férias.

ORCID: https://orcid.org/oooo-0002-4759-8244

Email: catarinafmfranco@gmail.com

Morada: Rua Alegre ${ }^{\circ} 431^{\circ}$ dto. 1495-005, Algés, Portugal

Fábio Anunciação é mestrando em Sociologia no Instituto Superior de Ciências Sociais e Políticas da Universidade de Lisboa (ISCSP-ULisboa). É licenciado em Ciências da Comunicação pela mesma faculdade e venceu o prémio de mérito de melhor aluno graduado em 2018.

ORCID: https://orcid.org/oooo-0001-8782-8481

Email: fabio.nogueira.anunciacao@gmail.com

Morada: Rua 25 de Abril, 25. 2605-164 Belas, Portugal

Maria João Cunha é licenciada em Comunicação Social e mestre em Sociologia pelo ISCSP, Universidade de Lisboa. Doutora em Ciências da Comunicação, na especialidade de Sociologia da Comunicação com tese sobre representações e impactos dos media. Professora Auxiliar no ISCSP, Universidade de Lisboa. Membro co-fundador e investigadora integrada do Centro Interdisciplinar de Estudos de Género (CIEG), em matérias relacionadas com género e comunicação. Foi co-coordenadora da secção de Género e Sexualidade da APS até 2018. Revisora para revistas científicas na área da comunicação, é autora, para além de artigos científicos, das obras A imagem corporal (2004), Sociologia da Comunicação (2011) e Corpo e imagem na sociedade de consumo (2014), entre outros.

ORCID: https://orcid.org/o000-0002-0325-5709

Email: mjcunha@iscsp.ulisboa.pt

Morada: Rua Almerindo Lessa, 1300 - 666 Lisboa, Portugal

* Submissão: 20/12/2019

* Aceitação: 19/04/2020 